\title{
Study of Thresholds to Burning in Surface Grinding Process
}

F. R. L. Dotto

and E. C. Bianchi

Lab. of Data Acquisition and Signal Processing Department of Electrical Engineering,

Department of Mechanical Engineering São Paulo State University - Unesp Av. Luiz Edmundo C. Coube S/N, Vargem Limpa 17033-360 Bauru, SP. Brazil aguiarpr@feb.unesp.br em_casa@uol.com.br bianchi@feb.unesp.br
This work aims at finding out the threshold to burning in surface grinding process. Acoustic emission and electric power signals are acquired from an analog-digital converter and processed through algorithms in order to generate a control signal to inform the operator or interrupt the process in the case of burning occurrence. The thresholds that dictate the situation of burn and non-burn were studied as well as a comparison between the two parameters was carried out. In the experimental work one type of steel (ABNT-1045 annealed) and one type of grinding wheel referred to as TARGA model $3 T G 80.3-N V$ were employed.

Keywords: Grinding, monitoring, burning, acoustic emission, electric power

\section{Introduction}

In metal mechanics industry grinding is usually the final process of a precision component. This process is used for production of parts of different materials, demanding low surface roughness, control of dimensional and form errors of the parts, maximum tool life with minimum time and costs (Aguiar, 1997 [2]).

The surface grinding process is not very dominated technologically yet. This perhaps has origin in the erroneous faith that the process is very complex to understand due to multiplicity of cutting edges and its irregular geometry, high speed of cut, and small depths of cut that vary from grain to grain.

According to Aguiar (1997 [2]), the chip removal in the surface grinding process doesn't happen in the same way found in those more conventional operations such as milling and turning. In these operations the tool has defined geometry of cut, while in grinding the tool presents many cutting edges, that is, irregular cutting geometry. The great amount of variables involved in the process as well as the constant change in cutting geometry make difficult the choice of the grinding conditions that facilitate the desired results.

Damages caused in the workpiece are of high cost, once every previous process, besides the own grinding are lost when a part is damaged in this stage. The most common damages in the grinding operation are burning, cracking and/or undesirable residual stresses. In the case of metals, the main cause of damages is the excessive thermal entrance into the ground surface of the part.

The need of effective reductions of costs aside the increase of quality of the parts produced requires the implementation of more intelligent systems in industrial environments. Therefore, the control of the real damages in the grinding process is of great interest for all dependent industries on this process, thus leading to a lower rate of scraps and consequently to a lower cost of production.

According to Malkin (1989 [6]), the high temperatures generated in the grinding zone can cause some types of thermal damages to the part, for example burning (in the case of steel), excessive tempering of the superficial layer with possible rehardening and increase of the brittleness, undesirable residual stresses of traction, reduction of the fatigue strength and cracks. It is generally necessary to reduce the grinding power in order to attenuate the restriction of thermal damages.

The coolant has also an important effect as a lubricant. Direct lubrication with grinding fluids becomes mainly important in creep-

Paper accepted May, 2005. Technical Editor: Atila P. Silva Freire. feed grinding (Malkin, 1989 [6]). Some analyses of heat transference indicate that the use of a faster work speed, keeping the same removal rate would lower the temperature and reduce the thermal damage, but this is not always true in practice.

The fundamental difficulty of controlling damages caused in the grinding process is the lack of a reliable method in supplying feedback in real time during the process. Acoustic emission and electric power signals together combined have successfully been used in determining indicative parameters when burn takes place (Aguiar et al., 2002 [1] / Aguiar, 1997 [2] / Aguiar et al., 2003 [4]). Once these signals are processed and combined properly, they allow online implementation of a burn monitoring system, optimizing the grinding process. This would be of great benefit for the dependent companies on this process, once the quality demand and international competitiveness grow more and more with the world globalization (Aguiar, 1997 [2]).

In his doctorate thesis in 1997, Aguiar (1997, [2]) established the DPO parameter for detection of superficial burning in surface grinding (Aguiar, 1997 [2]). This parameter is the product of the standard deviation of the root mean square (RMS) acoustic emission signal for each grinding wheel pass (SAE) by the maximum value of the power level in the current pass (MAxpot). The "Eq. (1)” shows this relationship.

$$
D P O=S A E \times M a x p o t
$$

According to Aguiar (1997, [2]), the behavior of the DPO parameter revealed an increase along the passes of the grinding wheel until the moment of burning, thus, presenting a more expressive characteristic to detect burn than acoustic emission and electric power signals alone. The DPO parameter demonstrated to be efficient at detecting the superficial burning and will be able to help the industries in the burning monitoring in surface grinding process.

Aguiar et al. (2002 [1]) developed another important parameter to detect the superficial burning occurrence in grinding, the FKS parameter. Some researches (Aguiar, 2002 [1] / Aguiar, 1997 [2] / Dotto et al., 2002 [5] / Pansanato et al., 2002 [7] / Aguiar et al., 2002 [3] / Aguiar et al., 2003 [4]) have demonstrated the association of statistical tools with the tangential cutting force and acoustic emission can help a lot in obtaining parameters and thus avoiding damages caused by burning. The FKS parameter is calculated by the ratio between the maximum cutting force (FcMax) and the multiplication of skew S(.) and kurtosis $\mathrm{K}($.) of the RMS acoustic emission (AE) signal for each grinding pass as shown in “Eq. (2)”. 


$$
\mathrm{FKS}=(\mathrm{FcMax}) /[\mathrm{S}(\mathrm{AE}) \cdot \mathrm{K}(\mathrm{AE})]
$$

The FKS parameter has demonstrated to be very sensitive to variations in grinding conditions and, therefore, it revealed to be efficient at detecting superficial burning of the part.

Thus, a comparison of the efficiency between the DPO and FKS parameters becomes of utmost importance for the same grinding conditions. This comparative study will certainly help a lot the grinding-dependent companies, and serious problems, as such grinding burn, could be attenuated through a monitoring system employing the most effective parameter studied.

The development of an intelligent system to detect burning is still a challenge for researchers. Thus, this work aims at not only doing a comparative study between DPO and FKS parameters but also developing a software that will acquire the acoustic emission (RMS) and electric power signals and process them using algorithms to calculate both DPO and FKS parameters. In the case of burning occurrence, the system will send a control signal to the operator or Computerized Numerical Control (CNC), informing the burn has taken place. Furthermore, the system will be able to make information available via Internet about the entire process.

\section{Concepts of Superficial Burning in Grinding Process}

One of the most common types of thermal damages in grinding process is the burning of the part. When the superficial burning of the part is initiated, there is a trend of growth of metallic particle adhesion in the abrasive grains of the grinding wheel, having as consequence the increase of the grinding forces. This increase of forces causes the deterioration of superficial quality of the part, turning out the increase of the diametrical loss of grinding wheel with the subsequently increase of its volumetric wear. According to Malkin (1989 [6]), the superficial burning of the part influences on the alteration of the microstructure of the ground material.

From the accomplishment of microhardness measurements in the annealed steel subsurface, it has been observed the superficial burning induced by the grinding process is accompanied by a reaustenitization process of the material. When grinding burn doesn't take place for the mentioned material, there usually exists a softening of the material close to the surface because temperatures below the austenitization have been reached. Upon grinding burn, rehardening of the material also occurs, which is due to the reaustenitization accompanied by formation of untempered martensite. This can be evidenced through the metallographic analysis, resulting in the increase of the surface microhardness. Metallurgic evidences and measurements of microhardness suggest that the visible burn threshold is coincident with the onset of that for austenitization. According to Malkin ( 1989 [6]), the superficial burning of the part, observed for bearing steels brings an adverse aspect with regard to the limit of fatigue strength and consequent reduction of the number of cycles of these steels after grinding operation. This behavior is attributed to the formation of nonannealed martensite generated in the burning superficial process, in function of the heating at the austenitization temperature and fast cooling without posterior relief of stresses (annealing).

There is another front of researches that defends the film boiling phenomenon due to the increase of the temperature in the grinding zone (Aguiar, 1997 [2]).

Shafto postulated that the fast increase in temperature is characteristic of a phenomenon known as burn-out, which occurs in boiling pipes (Shafto, 1975 [9]). At a critical temperature related to the burn-out temperature, a collapse in the mechanism of heat transference takes place, which results in a fast increase of temperature. When the temperature reaches values around $100^{\circ} \mathrm{C}$, the water enters the boiling causing bubbles on the heater surface.
An increase beyond the boiling temperature provokes the union of the bubbles, forming a vapor layer on the surface known as Filmboiling. The transference of heat through this film is much more difficult, thus causing a sudden increase of temperature.

Yasui, H. and Tsukada, S. (1983, [10]) measured the temperature on the surface of the part using oil and water as coolant and also dry grinding. They have observed that at temperature above of the boiling point of each fluid, the surface of the part reached the corresponding temperature to which was verified for dry grinding. In other words, the fluids were no longer effective. In a posterior study, Salmon (1988, [8]) experimentally observed the formation of a vapor film on the surface of the part, immediately below the contact zone.

\section{The Control of the Process}

All the process of burning detection in this work was based on the setup shown in "Fig.1".

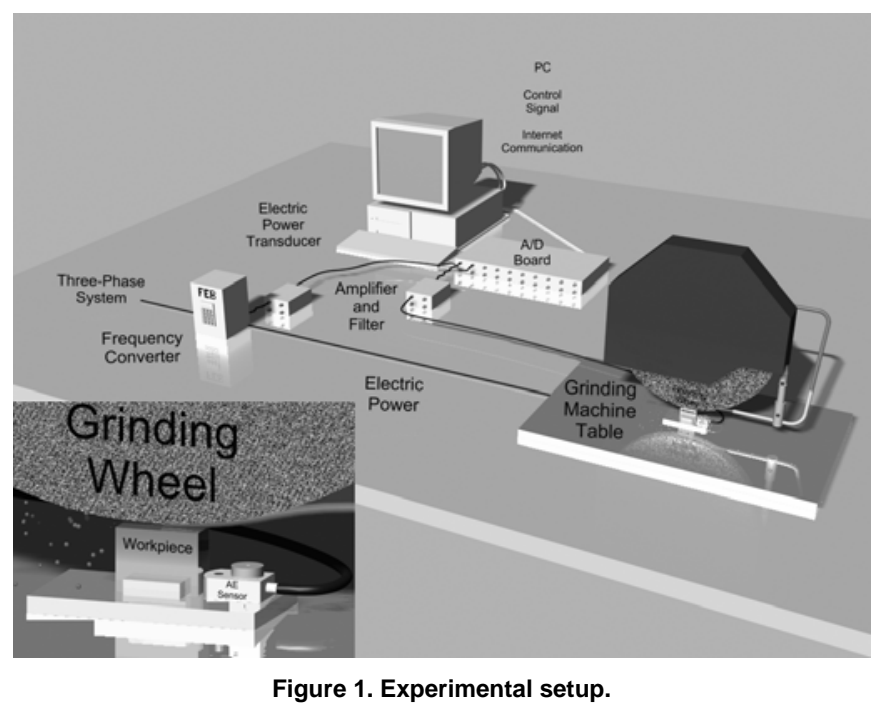

This research project was carried out through a methodology of development and experimentation, which was based on the construction of a smart system. The system consists basically of a computational program development using Visual Basic language that will accomplish the signal acquisition of acoustic emission and electric power of the grinding wheel's motor drive, and further processing these signals through DPO and FKS parameters defined by Aguiar et al. (2002 [1]). A control signal will be sent to the operator or CNC in the case of burning occurrence and the online process monitoring via Internet will be feasible. Moreover, the construction of an experimental setup was carried out to allow the burn detection through the determination, measurement and control of input parameters and output variables as well as all necessary data of each test saved onto hard disk of the computer for further analysis.

We can, therefore, divide the process in 3 basic stages:

- The power and acoustics emission (AE) signals are collected by the National Instruments data acquisition board.

- The software developed (Grinding Analysis) manages and acts in the process informing the operator in the case of burning occurrence.

- All information of the process is available for future observation through the Internet and changes can be made whenever is needed. 


\section{Software Characteristics}

The main characteristics of the software developed are:

- Versatility of software integration with Windows environment, besides computer networks and Internet.

- Friendly Interface between the software with the data acquisition system and with other programming languages, through DLL.

- Easiness of control system implementation aiming at data sharing.

- Supervision and management of burning detection in grinding process.

- Remote control (Internet).

- Monitoring.

- The software allows the detection of the burning point, making data available for control in dedicated applications and those to which demand alterations during the process (change in parameters) or even those that need a more rigorous tracking.

\section{Software Description (Grinding Analysis)}

The software for the process control was developed using the Visual Basic language. This software is composed of several stages that facilitate the user to determine DPO and FKS parameters in real time. The software collects information through a National Instruments data acquisition board at 1000 samples per second rate. At every instant, the software calculates DPO and FKS parameters and plots them into a graph. According to a database pre-defined, the software verifies the DPO and FKS level informing the operator if certain limit was reached.

A remote database having the DPO and FKS limits was developed through a very exhaustive simulation and here unveiled. It was generated previously relating the diverse types of materials, type of grinding wheel, cutting fluid etc ("Fig. 2"). This database will be available in an ASP server to be accessed via Internet, together with the results of the control.

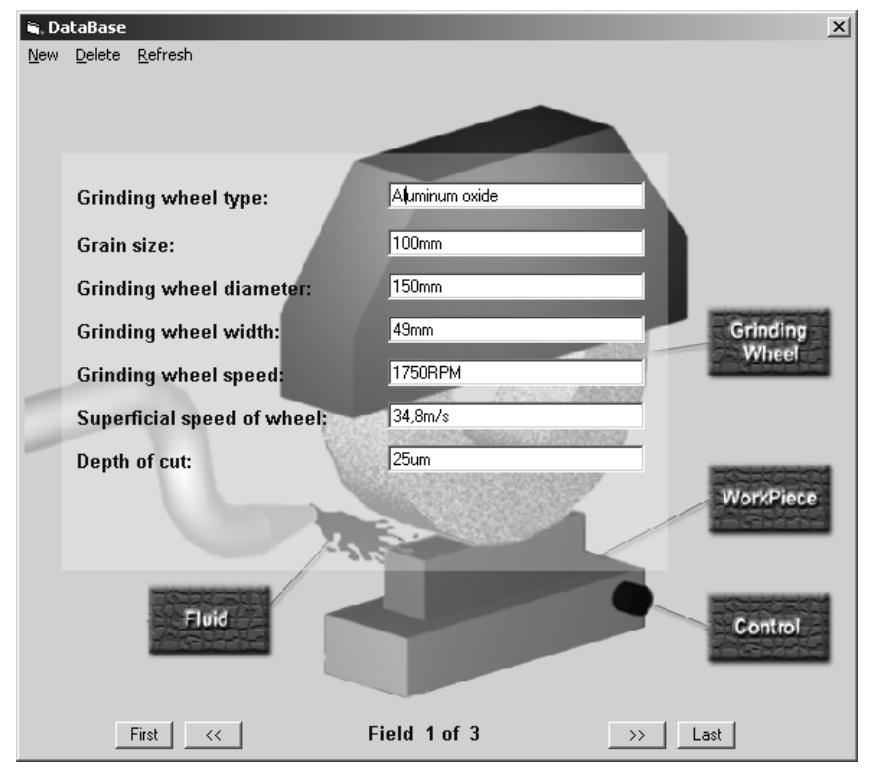

Figure 2. Remote database.

Another block was attached to the software to allow the data analysis after the process control. When the process control is being executed, the data collected from the data acquisition board are stored in data files simultaneously, becoming the data available for further analysis through this block. The FFT calculation, maximum value, minimum value, average, standard deviation etc are some of many tools available in this block (Wave Analysis).

The appearance of the Wave Analysis window is shown in Figure 3.

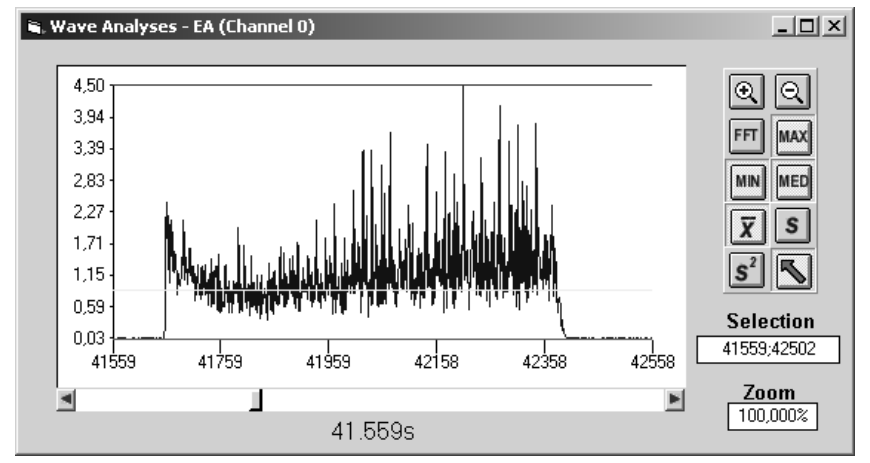

Figure 3. Wave analyses. FFT.

Figure 4 shows the window that allows the calculation of the

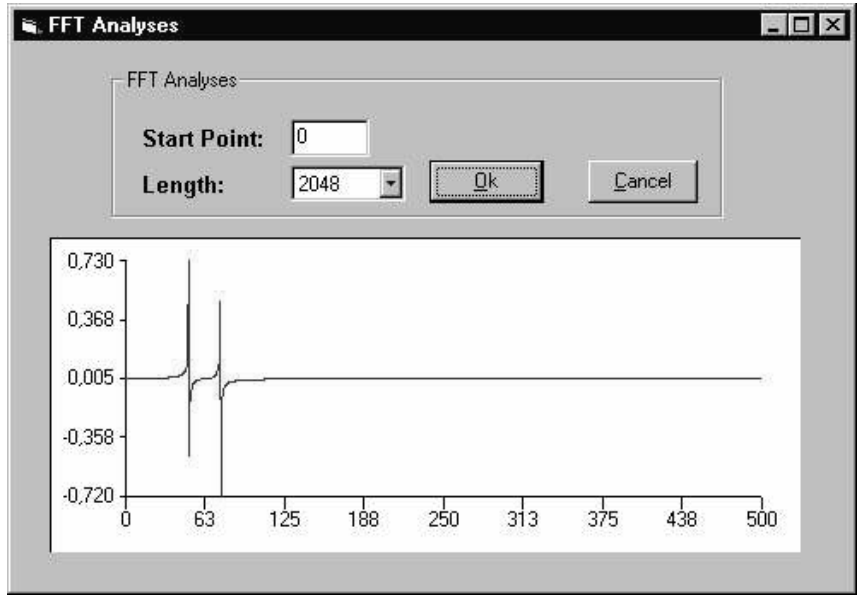

Figure 4. FFT analysis.

The software allows the user the complete control of all analog inputs and outputs of the data acquisition board as well as relates each input or physical output with the correspondent logic ("Fig. 5”). Thus, other signals can be read through the data acquisition board for further processing and analysis like temperature, speed etc.

It can be clearly seen, in figure 5, two channels of hardware (Channel 0 and Channel 1) mapped through logical names EA and POT respectively. In this window is also possible to change the general proprieties of the software by just accessing each of those options (General Information, Database, Graphic Properties, Hardware and Advanced).

In order to get the burn occurrence detection successfully, it is imperative the definition of a burn threshold previously studied that will be presented in this paper. This threshold must be adjusted in the software so that an action can be taken to interrupt the process or even to alert the machine operator if the threshold has been reached, meaning the grinding burn occurred. The window "Processing Data On-Line" ("Fig. 6") shows the software running while the data acquisition and online processing of the acoustic emission and power signals take place. It is important to observe that the arrow 
defines this threshold and the user may change its location according to his need.

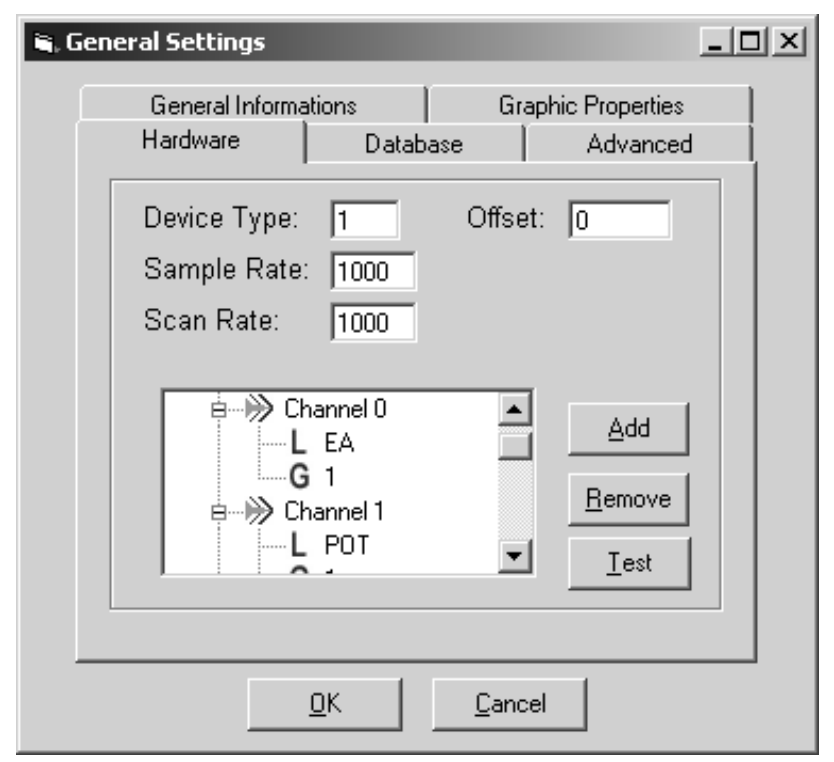

Figure 5. General settings.

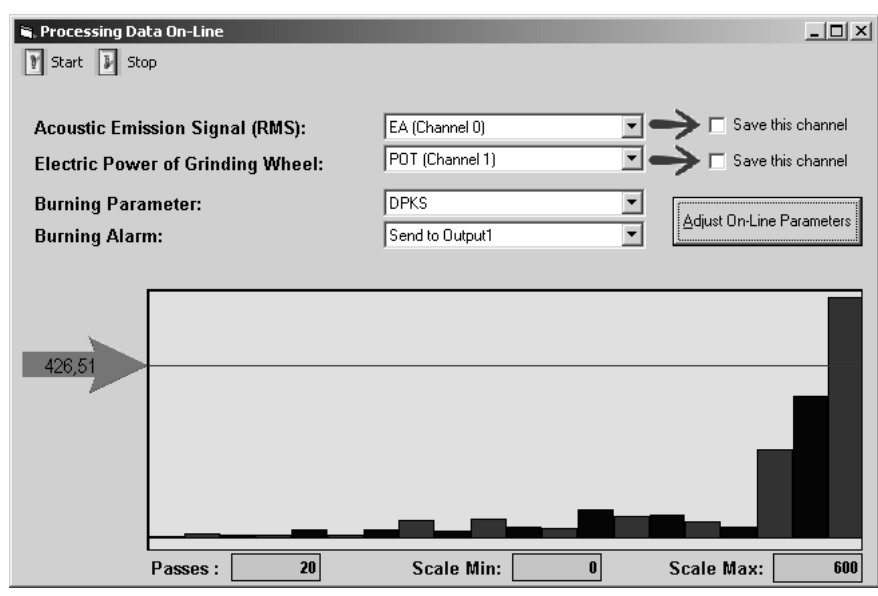

Figure 6. General settings.

The database is available for examination while the control of the process is occurring. The changes made by the user are updated remotely and simultaneously.

\section{Results}

Tests were carried out on several workpieces in order to find out the burning threshold, allowing a further comparison between the DPO and FKS parameters for each situation.

The characterization and classification of the burn were visually made during the grinding operation. Right after each grinding pass the surface of the workpiece was classified as non-burn, slight burn, medium burn and severe burn, according to the workpiece surface coloration.

Table 1 shows pictures in which different patterns of colors obtained in the tests are presented.
Table 1. Patterns of colors used in the burn classification.

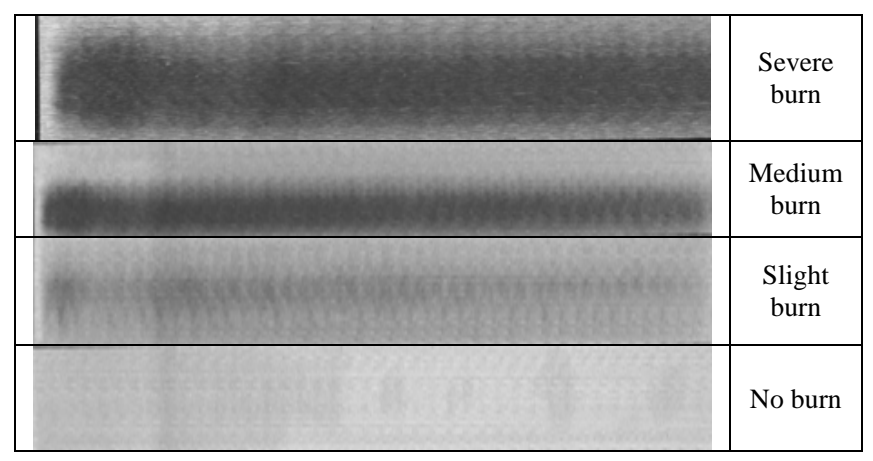

A number of 10 runs were carried out in laboratory for ABNT 1045 steel in a surface grinding machine with ceramic aluminum oxide grinding wheel referred as TARGA, from Norton Manufacturer. Each test was concerned to 25 grinding passes (plus spark-out cycles) or until the occurrence of severe burn. Some significant tests were picked, which are presented as following.

From those tests, it was also possible to define the thresholds to burn occurrence for online detection.

Table 2 shows the grinding conditions for the tests carried out which allowed the establishing of the thresholds to burn.

Table 2. Grinding conditions.

\begin{tabular}{|l|l|l|l|}
\hline \multicolumn{4}{|c|}{ ABNT 1045 Steel } \\
Wheel 3TG80.3-NV (TARGA) and Emulsion as Coolant \\
\hline$a=45 \mu \mathrm{m}$ & $a=40 \mu \mathrm{m}$ & $a=35 \mu \mathrm{m}$ & $a=30 \mu \mathrm{m}$ \\
$V_{w}=0,120 \mathrm{~m} / \mathrm{s}$ & $V_{w}=0,120 \mathrm{~m} / \mathrm{s}$ & $V_{w}=0,120 \mathrm{~m} / \mathrm{s}$ & $V_{w}=0,120 \mathrm{~m} / \mathrm{s}$ \\
$V_{s}=31,8 \mathrm{~m} / \mathrm{s}$ & $V_{s}=31,8 \mathrm{~m} / \mathrm{s}$ & $V_{s}=31,8 \mathrm{~m} / \mathrm{s}$ & $V_{s}=31,8 \mathrm{~m} / \mathrm{s}$ \\
$h_{e q}=0,170 \mu \mathrm{m}$ & $h_{e q}=0,151 \mu \mathrm{m}$ & $h_{e q}=0,132 \mu \mathrm{m}$ & $h_{e q}=0,113 \mu \mathrm{m}$ \\
& & & \\
\hline
\end{tabular}

Where $V_{w}$ represents the table speed or workpiece speed, $V_{s}$ the tool speed or grinding wheel speed, $h_{e q}$ the equivalent thickness and $a$ represents the depth of cut.

All the parameters were kept constant except the depth of cut, which varied for each test carried out as shown in Table 2 .

Figures 7 to 14 show the DPO and FKS calculated for each grinding condition studied. It can be observed that each figure is divided in three parts: acoustic emission, electrical power of the grinding wheel motor drive and the processed parameter.

On the top of each figure the grey rectangles express the pass regions of the acoustic emission signal whereas in the middle of each figure grey rectangles show the boundary of the valid regions regarding the electrical power signal passes. The extraction of the grinding passes is based upon a specific algorithm developed for this purpose, in which the passes are detected automatically and selected by a signal processing with no user interference at all.

The lines in the electrical power plots show the behavior of the function in time and are utilized by the algorithm that detects the grinding passes in order to set across the valid region. For all graphics ("figs. 7 to 14") a threshold to burn was sought, which is represented by the arrow. However, a region between the burning and non-burning occurrence was not possible to define completely for those graphics in which the FKS is calculated and shown, so the arrow is not shown in some graphics.

The grinding passes extracted from acoustic emission signal are associated with those extracted from the electrical power signal in order to properly calculate the parameter. A window is used for this purpose with a time scale in common for both signals. 


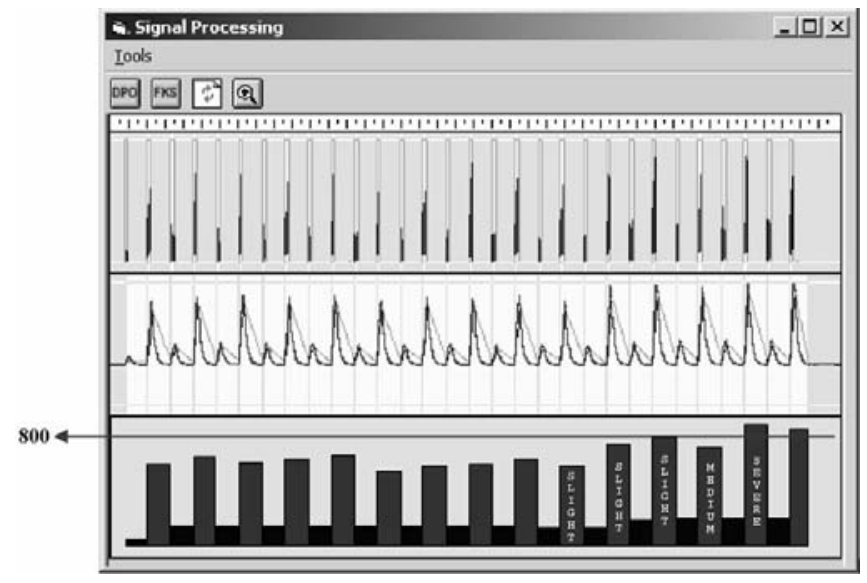

Figure 7. DPO parameter calculation - ABNT1045 steel with heq=0,170 $\mu \mathrm{m}$.

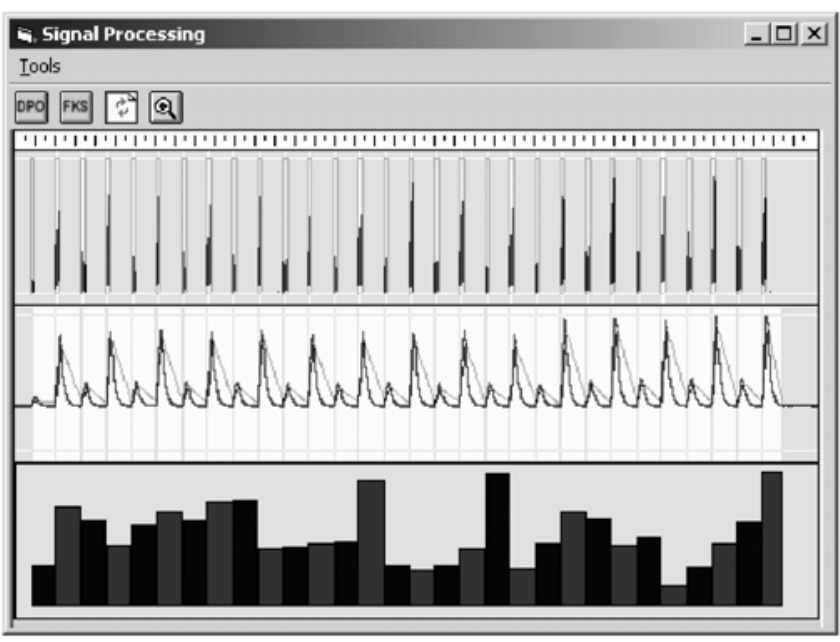

Figure 8. FKS parameter calculation - ABNT1045 steel with heq=0,170 $\mu$ m.

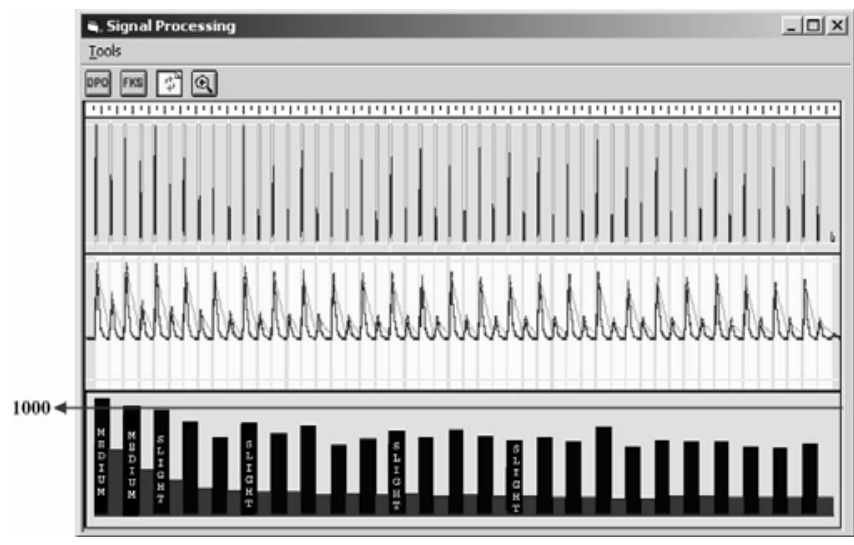

Figure 9. DPO parameter calculation - ABNT1045 steel with heq=0,151 $\mu \mathrm{m}$.

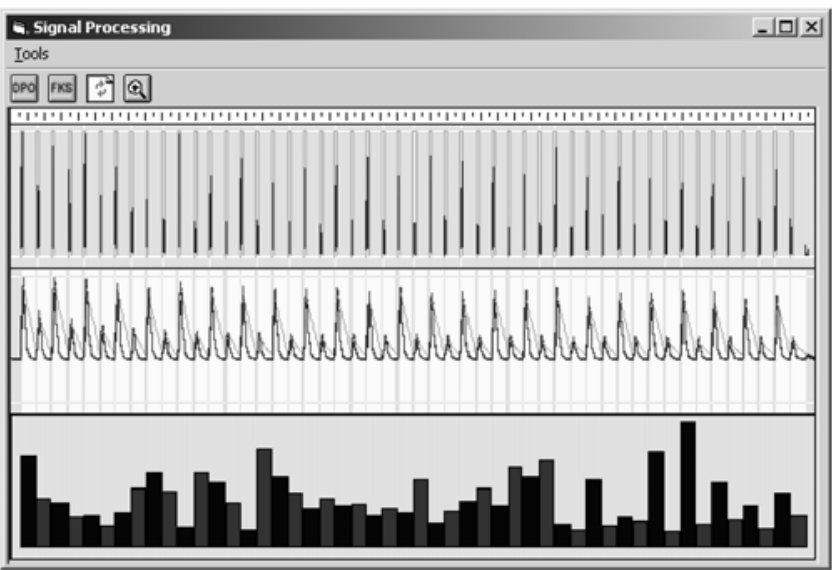

Figure 10. FKS parameter calculation - ABNT1045 steel with heq=0,151 $\mu \mathrm{m}$.

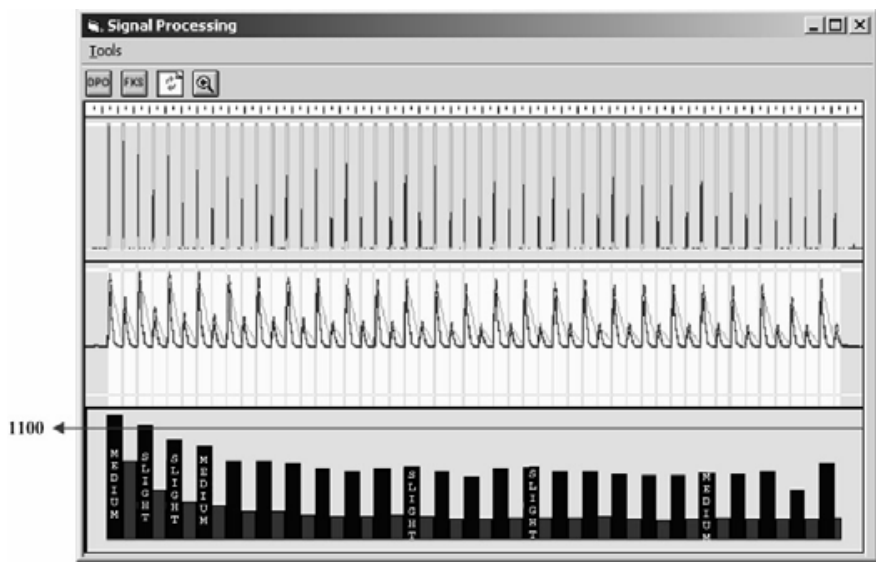

Figure 11. DPO parameter calculation - ABNT1045 steel with heq=0,132 $\mu \mathrm{m}$.

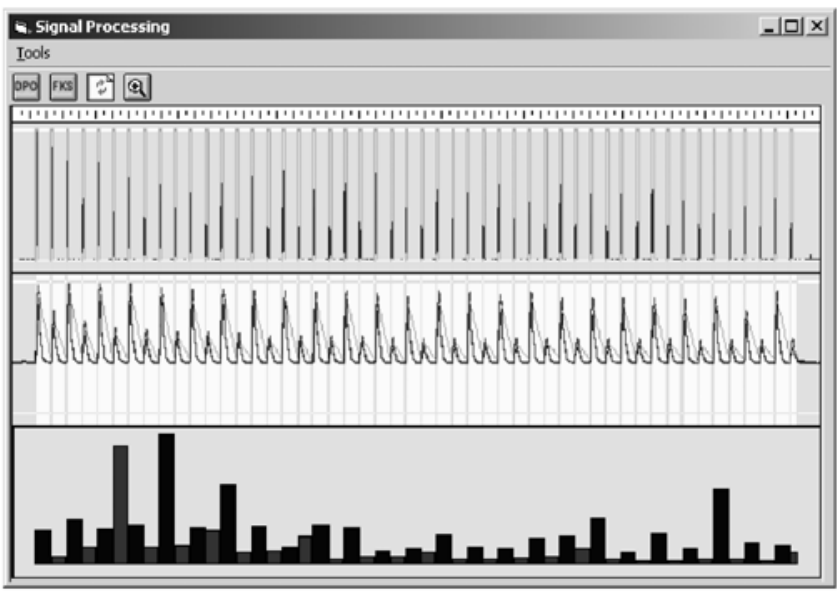

Figure 12. FKS parameter calculation - ABNT1045 steel with heq=0,132 $\mu \mathrm{m}$. 


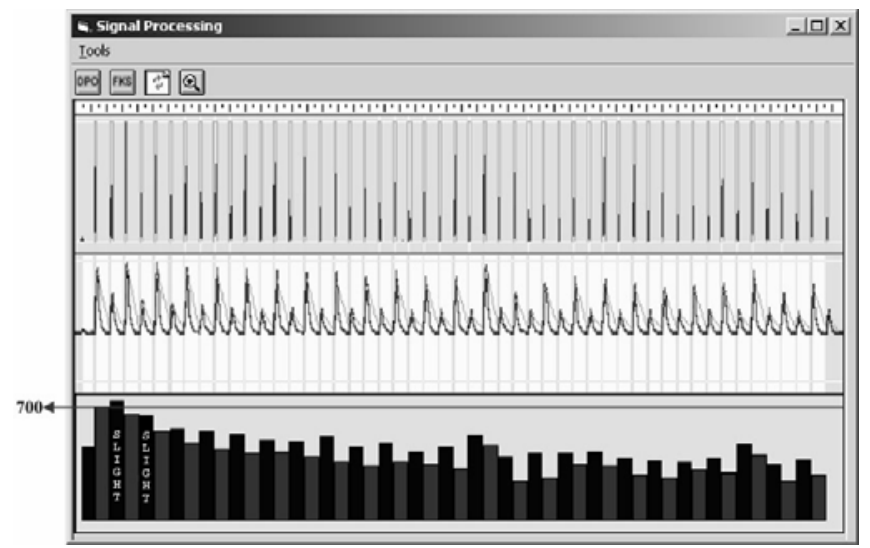

Figure 13.DPO parameter calculation - ABNT1045 steel with heq=0,113 $\mu \mathrm{m}$.

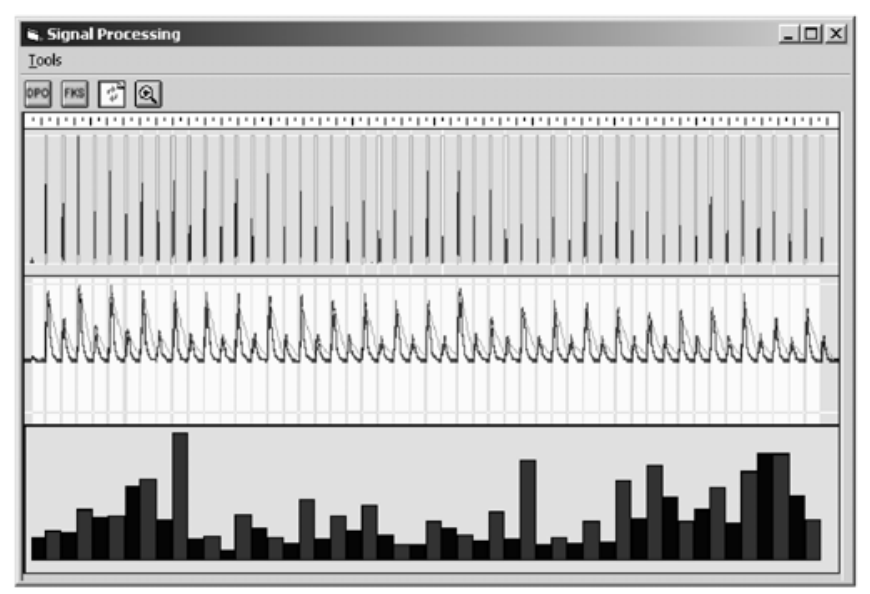

Figure 14. FKS parameter calculation - ABNT1045 steel with heq=0,113 $\mu \mathrm{m}$.

The results obtained show that none of the parameters analyzed was completely effective to detect the burn occurrence. In other words, it was not possible to determine a threshold between burn and non-burn state $100 \%$ trustful.

However, the DPO parameter has shown more effective and presented an increase of values regarding the other passes of the same test for almost every time on which the visual burn occurred.

Although the FKS parameter has presented more pronounced peaks in some burn situation as shown in "fig. 8", it has also presented peaks in places where burn did not take place and then it did not indicate any change when burn occurred as shown in "figs. 10,12 and $14 ”$.

These results, however, should not be extrapolated and neither generalized because the characteristics of the parameters analyzed are valid for the grinding wheel and material employed.

The ABNT 1045 steel is a kind of steel of ductile/fragile transition, which makes difficult any analysis via acoustic emission. Besides, the grinding wheel TARGA has high capability of selfdressing, which in burn situation does not allow the cutting power to increase enough. As the two parameters studied in this work are based on the acoustic emission changes and the supposed increase of the cutting power at the burn occurrence, it is not difficult to acknowledge there is a great difficulty on detecting burn under these conditions. New parameters are being studied by utilizing the developed software in order to improve the burn detection.

The arrows shown in "figs. 7, 9, 11 and 13" indicate the thresholds to burn proposed for the DPO parameter. However, it was not possible to determine a threshold to burn for the FKS parameter. These defined regions correspond to a safe point where the workpiece burn has in fact occurred. Below this point the burn might also occur but it is not possible to predict its real occurrence based upon the methodology employed in this work.

Table 3 shows a summary of all results obtained during the tests.

Table 3 - Summary of all results.

\begin{tabular}{|c|c|c|c|c|}
\hline \multicolumn{5}{|c|}{ Burn detection regarding the parameters studied } \\
\hline $\mathbf{h}_{\mathbf{e q}}$ & DPO & Threshold & FKS & Threshold \\
\hline $0,170 \mu \mathrm{m}$ & Good & 800 & Bad & None \\
\hline $0,151 \mu \mathrm{m}$ & Good & 1000 & Bad & None \\
\hline $0,132 \mu \mathrm{m}$ & Good & 1100 & Bad & None \\
\hline $0,113 \mu \mathrm{m}$ & Good & 700 & Bad & None \\
\hline
\end{tabular}

In table 3, the word "Good" means the parameter was successfully effective; "Bad" means the parameter was useless; and "None" means a threshold was not possible to define.

\section{Conclusions}

Based on all experiments accomplished, the software presented a good performance, allowing an immediate calculation of the DPO and FKS parameters.

It has been noticed the DPO parameter can be easily employed to detect the burn occurrence. However, the FKS parameter has presented very bad results for those grinding conditions, which make it a useless parameter to detect burn in grinding.

It is important to point out that the developed system can be implemented into practice and then turning out a unique and innovator project in the manufacturing area.

The proper position of the acoustic emission and power sensor is also very important, for the calculated parameters used a well defined grinding condition. The change in position of the acoustic emission sensor, for instance, may compromise the entire process of online burn detection.

The database is constantly being updated and new records are included for each experiment. The Internet resources offered by the software are in test phase to be added to the software package soon.

\section{Acknowledgement}

The authors want to express their thankfulness to Fundação de Amparo à Pesquisa do Estado de São Paulo - FAPESP, Proc. 01/11353-4 and Proc. 02/09499-3 for the financial support given to this work.

\section{References}

[1] Aguiar, P. R. et al., "A integridade superficial da peça monitorada por emissão acústica e potência elétrica no processo de retificação (in Portuguese)". 8as Jornadas Portuguesas de Tribologia - Novos Desenvolvimentos da Tribologia: Análise Teórica e Aplicada em Processos Industriais. Universidade de Aveiro, Portugal, 08 e 09 de maio de 2002. p. 245 - 249.

[2] Aguiar, P. R., "Burn Monitoring in Grinding Process by utilizing the Acoustic Emission and Electric Power Signals (in Portuguese)”, Doctorate thesis, Escola Politécnica da USP, 1997.

[3] Aguiar, P. R. et al., "A detecção da queima por redes neurais na retificação cilíndrica externa (in Portuguese)". 8as Jornadas Portuguesas de TRIBOLOGIA - Novos Desenvolvimentos da Tribologia: Análise Teórica e Aplicada em Processos Industriais. Universidade de Aveiro, Portugal, 08 e 09 de maio de 2002. p. 239 - 243.

[4] Aguiar, P. R., "Controle Automático de Danos Térmicos na Usinagem por Abrasão através do Processamento de Sinais de Emissão Acústica e Potência Elétrica (in Portuguese)". Tese de Livre-docência apresentada na Universidade Estadual Paulista - Unesp, Bauru-SP, 2003.

[5] Dotto, F. R. L. et al., "Sistema inteligente de detecção automática on-line de danos térmicos no processo de retificação com monitoramento via 
Internet (in Portuguese).” In: Congresso Brasileiro de Automática (CBA), 14; Natal - RN, de 2 a 5 de setembro de 2002. p 3029 - 3034 (em CD $\mathrm{ROM})$

[6] Malkin, S., “Grinding Technology - Theory and Applications of Machining with Abrasives”, Ellis Horwood Limited Publishers, Chichester, Halsted Prtess: a division of John Wiley \& Sons, 1989.

[7] Pansanato, L. et al., "O processamento do sinal bruto de emissão acústica e velocidade de corte na detecção de dano térmico na retificação plana (in Portuguese)”. Congresso e Exposição Internacionais de Tecnologia da Mobilidade - SAE Brasil 2002, 11º; São Paulo - SP, 19 a 21 de novembro de 2002. Anais do SAE Brasil 029. São Paulo: 6 páginas (em CD - ROM). SAE Technical Paper Series 2002-01-3528 P. ISSN 0148-7191.

[8] Salmon, S. C., “Unpublished work”, University of Bristol, 1988.

[9] Shafto, G. R., Creep Feed Grinding, Ph.D. Thesis, University of Bristol, 1975

[10] Yasui, H. and Tsukada, S., "Influence of Fluid Type of Wet Grinding Temperature”. Bull. Japan Soc. of Prec. Eng., Vol. 17, No. 2, pp. 133-134, 1983. 